\title{
Correction to: Multicopter Design and Control Practice
}

\section{Correction to:}

Q. Quan et al., Multicopter Design and Control Practice, https://doi.org/10.1007/978-981-15-3138-5

The original version of the book has been revised. The erratum book has now been updated with the below-listed corrections.

\begin{tabular}{l|l}
\hline Category & Occurnces \\
\hline Textual (replacement) & 143 \\
\hline Textual (deletion) & 28 \\
\hline URL corrections & 16 \\
\hline Equation & 18 \\
\hline Figure & 9 \\
\hline Table & 10 \\
\hline
\end{tabular}

